\title{
Examining Teacher Perceptions of the Appalachian Dialect in One Rural Appalachian Elementary School
}

\author{
Kathy Brashears \\ Tennessee Technological University
}

\begin{abstract}
While numerous studies focus on dialect in educational settings, this research focuses on teacher perception of the Appalachian dialect in one rural elementary school. Data collected, mainly through interviews with educators, indicate that teachers sometimes view the Appalachian dialect as impeding their teaching of Standard English. Implications of the study include that teachers may benefit from professional development that provides opportunities for self-reflection on the way they teach and use Standard English as well as how they teach students to use different registers or code-switching skills. Through this type of professional engagement, teachers may better understand their role in modeling Standard English while honoring the Appalachian dialect.
\end{abstract}

Key Words: dialect, Standard English, code-switching, Appalachia

Having been raised in rural, East Tennessee, I am intimately familiar with Appalachian people, their ways, and their speech. Simply put, I am an Appalachian. For the purposes of this study, I am an insider. The subject of dialect for me, as for many Appalachians, is personal and represents a deep, enduring connection to place. In essence, our dialect promotes a sense of belonging. However, sometimes the Appalachian dialect may be looked upon as a hindrance even within the Appalachian community itself. Specifically, in the school setting, the Appalachian dialect may be viewed as inferior. Wolfram \& Schilling-Estes (2006) explain that linguistic inferiority occurs when members of the dominant society view the speech of other groups as being of a lesser quality than their own. Such a perspective is more common in speakers of the 'standard' variety of a language due to the differences of various groups in their status and power relations (Lippi-Green, 1997).

To understand how teachers in one Appalachian area view the Appalachian dialect, I interviewed teachers in an elementary school, located within the Appalachian region as defined by the Appalachian Regional Commission (ARC).

\section{Rural Appalachia}

The Appalachian region is located in the following states: Kentucky, West Virginia, Mississippi, Alabama, Georgia, South Carolina, North Carolina, Virginia, Tennessee, Ohio, Maryland, Pennsylvania, and New York (Obermiller \& Howe, 2000). While parts of these states and all of West Virginia make up the Appalachian region, there are three distinct areas northern, central, and southern.

According to Strange, Johnson, Schowalter, \& Klein (2012), rural areas are located within each of the fifty states: Rural schools make up 33\% of all American schools, and as many as 9 million students receive a rural education. In the Appalachian region $42 \%$ of the population is considered rural (ARC, 2012). Typical concerns for some rural areas are high student poverty and high school dropout rates, and these issues also pertain to the Appalachian region (Strange et al., 2012).

\section{Language of Appalachia}

Although the Appalachian region is home to many dialects and, as Speicher and Beilanski (2000) suggest, "speakers themselves produce various dialects of a given language" (p. 147), I will use the term "Appalachian dialect" when referring to the "distinctive sounds, syntax, and originality" (p. 999) Montgomery (2006) found in the speech throughout the Appalachian region. However, this is not to say that the Appalachian dialect does not bleed into the words we use in our writings or the ways in which we craft our written sentences. As with anything pertaining to culture, dialect cannot be neatly segregated into one specific area: it plays a part in our speech, stories, writings, music, family gatherings, and religion - just as assuredly as does the air we breathe.

According to Dial (1969),

The dialect spoken by Appalachian people has been given a variety of names, the majority of them somewhat less than complimentary. Educated people who look with disfavor on this particular 
form of speech are perfectly honest in their belief that something called The English Language, which they conceive of as a completed work unchanging and fixed for all time - has been taken and, through ignorance, shamefully distorted by the mountain folk. The fact is that this is completely untrue. The folk speech of Appalachia instead of being called corrupt ought to be classified as archaic. (p. 463)

Dial further (1969) explains that the influence of early Scottish and Irish settlers is apparent in both the words and sentence structure of Appalachians today. Barker (1995) notes the influence of Old English and references similarities between Appalachian dialect and the etymology of Chaucer. Just as in the UK to this day, each state or area in the Appalachian region in essence has its own dialect. Some writers describe this dialect as "southern speech" or country talk (Wilkinson, 1999). Still another researcher refers to the Appalachian dialect as the "phonological, morphological, and syntactic differences" between Appalachians and non-Appalachians (Reese, 1995, p. 493). However, for the purposes of this study, all of these dialects are referred to as the Appalachian dialect.

The Appalachian dialect invokes many unique and colorful descriptions. Wilkinson (1999) describes it as "a country twang- a melodic use of language that is distinctively wood burning stove, come in and sit a spell, patchwork quilt, summer swimming hole, sweet iced tea, you are always welcome here...warm" ( $p$. 186). In spite of what some consider a validation of the Appalachian dialect, the media continue to link the dialect with ignorance or low levels of intelligence (Montgomery, 2006; Reese, 1995; Wilkerson, 1999). Speicher and Beilanski (2000) share similar perspectives and report "studies demonstrate that people, even those who do not speak the standard, judge the standard superior to other dialects" (p. 148). Sadly, Montgomery (2006) concurs: “[S]ome mountain people also have accepted this negative evaluation of their English" (p. 1005).

Over the years I have chosen to remain in the Appalachian region, near my hometown, and to teach literacy courses in elementary education for many university students who, like me, will ultimately remain working in or near the same schools their families have traditionally attended. Because I share this sense of place or common bond with many of my students, some of whom are my former elementary school students and others former elementary and high school classmates, I find myself in a unique position to address the influence of dialect in our instruction and classrooms.

\section{The Influence of Teachers}

Although certainly not reflective of current views of the National Council of Teachers of English (NCTE), society at large tends to take a dim view of some dialects. For example, in 1917 NCTE expressed an interest in the sole use of Standard English within the United States by encouraging teachers to recite the following pledge with their students: "I promise that I will not dishonor my country's speech by leaving off the last syllable of words" (Smith, 2002, p. 29). In light of such sentiment, it is not surprising that, throughout history, students with an Appalachian dialect have typically been considered unsuccessful (Montgomery, 2006,). Language defines our origins (Wolfram, 1998). A person's background, character, and intellectual capacity are frequently inferred not only by society as a whole, but also by teachers. As Perry and Delpit (1998) acknowledge:

How teachers view the language of students and their families plays a significant role in teachers' expectations and respect for students' cultures.

Speaking a different dialect or language -- whether it is Ebonics, Spanish, or Tagalog -- should not prejudice teachers' attitudes toward children. But too often it does. (p. XIV)

To further complicate matters, some Appalachians resist acknowledging their informal register and go to great lengths to lose their dialect. Wilkinson (1999), for example, recounts how as a child she spent hours in front of the television trying to learn how to speak "properly" and to remove all that was "country" in her speech (p. 184). Others Appalachians, too, talk about taking pride in their heritage while striving to appear "non-hillbilly" and, to some degree, silencing their Appalachian "voice" (DeRosier, 2003; Dyer, 1998).

Coupling such findings with Perry and Delpit's (1998) observations, it seems logical to make two inferences. First, teachers need to be role models for the use of Standard English. Second teachers need to express positive attitudes toward all dialects, specifically, in relation to this study, the Appalachian dialect.

\section{Evidence of Dialect in Speech and Writing}

While acknowledging the work of Speicher and Beilanski (2000) in separating spoken dialect from written language, as with any language user, it is sometimes challenging to identify the line separating the two. However, mainly from my perspective of one who recognizes differences in her dialect and Standard English, my willingness to openly address dialectal issues stems from an encounter during my first year in college. While poking fun at the use of regional phrases and words like "pump knot" and "reckon", our 
instructor abruptly announced that we would only use Standard English in her class. While continuing her diatribe, she called my name and suggested that my East Tennessee 'talk' made me seem less than intelligent. Although not familiar with the term codeswitching, I learned of the concept on the spot! Exercising code-switching skills or using different registers simply means moving freely between one's given dialect and Standard American English as needed in a given situation (Cheatham, Armstrong, \& Santos, 2009).

Unfortunately, along with my former instructor, others share such narrow thinking regarding dialect. As Montgomery (2006) comments:

Too often one still finds the view that American dialects such as Appalachian speech are only modifications of Standard English 'incorrectly learned' due to social backwardness or even mental deficiency. Educators and linguistics have argued against these views for a long time, but the association of mountain English with impoverished, low-status speakers has resisted programs of its respectable heritage. (pp. 10041005)

Purcell-Gates (1995) offers additional evidence that the Appalachian dialect "is often used to characterize poor whites known variously as 'hillbillies,' 'hicks,' or 'ridgerunners"' (p. 123). Furthermore, "this dialect is strongly associated with low levels of education and literacy as well as a number of social ills and dysfunctions" (p. 123). Because of my exposure to such stereotypes, as an educated person and an educator, I cherish my Appalachian dialect, code-switch naturally, take pride in my heritage, and share my hard-earned insights with both my under-graduate and graduate students.

\section{Awareness of Dialect}

Recently, a teacher shared that she read I Ain't Gonna Paint No More (Beaumont, 1995) to her first graders. When I asked if she used this as an opportunity to talk about dialect and different registers, she replied, "We was just reading for fun." As this vignette illustrates, even today, some teachers in the Appalachian region remain unaware of their own dialect and, thereby, the impact of their dialect on their teaching of Standard English. However, Salantino (1995), along with Delpit (1998), suggest that effective teachers are aware of ways to help their students deal with their own dialect. In fact, Delpit, although mainly addressing African-American dialect, suggests that educators must seize opportunities to teach the use of informal and formal registers. Code-switching is one strategy that may be useful to students as they navigate between Appalachian dialect and Standard English.
Code-switching. There is a dearth of research on teacher attitude toward the Appalachian dialect, and code-switching and the Appalachian dialect. Several studies, however, focus on code-switching in regards to Ebonics (African-American vernacular dialect). Only parallels then, rather than hard conclusions, may be drawn from this body of literature in regards to code-switching and the Appalachian dialect.

Interestingly, Purcell-Gates (2002) suggests that "Nonstandard, socially marked dialects do prevent people from succeeding in the middle-class world, but they do not prevent people from learning to read and write" (p. 157). With this in mind, there is no reason that students who use a non-standard dialect, cannot also learn Standard English (Purcell-Gates, 2002). In fact, Baldwin (1998) maintains that such an approach is necessary since Standard English is a both a "political instrument...[and] proof of power" (p. 68) and because individuals who only use a non-standard dialect are less likely to be as economically successful as people who use Standard English. Although Barker (1995) may seem to trivialize the concept of codeswitching by referring to it as learning "to play the game" (p. 67), it is far from a simple practice and should be taught in non-episodic, thoughtful, reflective and purposeful approaches (Brice-Heath, 1983; Delpit, 1998).

On the other hand, some teachers believe that they cannot expect students who talk in non-standard dialects to read and write like members of the dominant culture. Some researchers are also critical of this viewpoint and argue that students become more appreciative of their home language when they have authentic opportunities to speak and write in Standard English as well as to exercise and develop codeswitching skills (Brice-Heath, 1983; Purcell-Gates, 1995; Speicher \& Beilanski, 2000; Taylor, 1998). Delpit (1998) further suggests that with such an approach, language diversity naturally becomes a part of the curriculum where students are taught to be cognizant as well as respectful of different languages and/or dialects. It seems reasonable to expect that teachers who successfully teach code-switching also tend to be open minded regarding culturally related issues. Such awareness is important, especially in the light of Delpit's (1998) observation that when teachers assess students' writing, they more often mark writing errors associated with dialect than any other types of errors. Furthermore, while Davidson, Howell, \& Hoekma (2000), studying African-American dialect, found teachers scored minority students' writings slightly higher than non-minority students, DudleyMarling and Searle (as cited in Csak, 2002) noted that teachers sometimes reject students' writing and words because of their desire "to 'teach' students to speak well" (p. 489). Whatever the case, these studies 
highlight the need for teachers to be cognizant and aware of their own biases, limitations, and expectations in teaching Standard English to all students.

\section{Lack of Research}

While several studies focus on Ebonics or other minority dialects, only a few studies, like Crotteau's (2007) work, focus on the Appalachian dialect, and still fewer on rural teachers' perceptions of the Appalachian dialect within the Appalachian region (Delpit \& Dowdy, 2002). However, Purcell-Gates (1995) and Brice-Heath (1983) did conduct wellrespected research studies in the Appalachian area regarding the literacy practices and development of people in and from rural areas. While Brice-Heath (1983) compared the literacy practices of two different Appalachian communities, Purcell-Gates (1995) highlighted family literacy practices of a young, Appalachian mother and her son. In essence, these studies provide insights about the Appalachian area and its people and reflect the complexity of language development within the region; thus they form a foundation on which to build further studies regarding both family and community literacy practices.

\section{Methods}

This research project focuses on teacher perception of dialect at a rural elementary school, Hollow Creek, located in the southern area of the Appalachian region. I chose this school because of its rural, Appalachian location and its success with standardized testing.

While conducting a literacy research project, I became intrigued with furthering my understanding of how teachers viewed the Appalachian dialect. Specifically, while interviewing them about literacy practices, I also asked teachers how they thought that society viewed the Appalachian dialect. Because dialect and the teaching of Standard English were central to this study, it seemed a natural choice to use qualitative research methods. I centered my data collection around interviews with twenty-five educators at the rural, Appalachian elementary school. In each interview, I asked the teachers the following questions.

1. How is the Appalachian dialect viewed in your school and in society?

2. How does the Appalachian dialect influence or impact your teaching?

I also gathered data from invited classroom observations in grades 1-5, where I noted when the teachers addressed or did not address dialectal issues. These observations were important in that they provided additional data to identify thematic strands during analysis.

In reporting this study, I have used pseudonyms for the names of the school, churches, community, and teachers. Pseudonyms were used for confidentiality reasons and, specifically, in an attempt to personalize the teachers' words and thoughts.

\section{Context}

For most Appalachians, sense of place and religion are paramount to their way of thinking (Constantz, 2006). It stands to reason then, to include a description of the site for this study and describe the presence of religious overtones to provide background for the reader to better visualize the study.

Located in a southern state and within a mid-size school district, Hollow Creek Elementary School perches on top of a large hill. Scattered houses, farmhouses, and trailers stretch along the road amongst a dozen or more Protestant churches and a sprinkling of grey weathered barns. Evidence of religious leanings are common, including many handmade and manufactured church signs, identifying Victory Tabernacle Church of God, Solid Rock Church, Nazarene Flatwoods Christian Church, Red Mile Baptist Church, the Great Shepherd Ministry Church, New Life Apostolic Church and House of Prayer, Outreach Christian Church, and Emmanuel Baptist Church. Although Hollow Creek is a farming community, much of the land looks poor with red clay gleaming amidst field rocks and patches of straggly grass. While some parts of the community are quite poor, other parts are relatively affluent. Close to the school are wide open fields and a log home with a green roof and a newly constructed stone chimney. While big pines, oaks, and sycamores help give the school an aged look, the freshly packed asphalt in the parking lot, the neatly kept grass, and the plants in front of the family resource sign, all indicate current attention to maintaining an attractive environment.

Just as religion marks the roadways leading to the school, so it marks the school itself. In hallways, classrooms, teacher talk, and students' writings religion is a daily presence. Black bound Bibles are found in offices and workrooms, and religious poems are displayed in the hallways and classrooms.

Sometimes gospel music can be heard playing softly in the background. In some classrooms, Bible verses are posted: for example, As ye would that man should do unto you, do ye also to them likewise: Luke 6:31. During lessons teachers make religious references, too. Some of these are humorous, as when one teacher referred to her students' final drafts as their Sunday go to meetin' papers. In this context, she was understood to mean that the papers should be their 
best work. More often, religion appears as a moral text, as when a teacher, while modeling how to write a personal narrative, referred to her grandmother as a fine Christian lady, and explained how she led an exemplary, moral life. Just as religion permeates teacher talk, it appears in discussions and student writings. A third grader, when having difficulty spelling Bible in a letter to his sick grandmother, correctly spelled the word as he softly sang: The B-I-B$L-E$, yes that's the book for me. I stand upon the word of God, the B-I-B-L-E! In another class, a fifth grader student wrote, One day after I had made my profession of faith and decided to follow Christ I got baptized. It was the most wonderful thing that has ever happened to me.

\section{Demographics}

One of ten elementary schools that comprise a midsized school district, Hollow Creek Elementary School is located in the southern Appalachian region as defined by the Appalachian Regional Commission (ARC). While the school is located in a rural area, it should be noted that it is within a one hour drive from a city of approximately 300,000 people. Hollow Creek Elementary School has a student population of around 500 students, kindergarten through grade 5.

Approximately $98 \%$ of the students are white. Also, while $17 \%$ of the population lives at or below the poverty line, around $50 \%$ of the student body qualifies for free and reduced meals.

Of the twenty-five educators interviewed at Hollow Creek Elementary School, twenty-four are originally from the Appalachian region and most were raised within a few miles of Hollow Creek Elementary School. Of those educators born and raised within the Hollow Creek community or a nearby community, only two are male. Their teaching experience ranges from no experience to twenty-five years or more, with most of the staff having taught for at least six to ten years.

\section{Findings}

Through interviews and some classroom observations, I addressed the following question: How do teachers perceive their responses to the Appalachian dialect? The findings highlight two important aspects. First, teachers need to be cognizant of their own language use so that they are better able to serve as role models in using Standard English. Secondly, teachers need to recognize the opportunity to honor both dialect and Standard English by consciously teaching students about different registers or code-switching skills. Interestingly enough, these findings mirror the findings presented in the review of the literature.

\section{Need for Dialectal Awareness}

The ways in which Appalachian teachers at Hollow Creek Elementary School address their students' Appalachian dialect in speech and writing are influenced by how they deal with their own dialect. For example, a third grade teacher, while teaching a phonics lesson, carefully enunciated, It's not $K|\breve{u}|$ ntucky. It's $K|\breve{e}|$ ntucky. These two sentences emphasize the difference between the short "u" sound and the short "e" sound and provide insight into the type of non-standard dialect used by some students and teachers at Hollow Creek Elementary. While Speicher and Beilanski (2000) argue that dialect in speech and writing should be addressed as separate issues, and Terry (2006) notes that "To date, relatively little is known about the relations between dialect use and spelling skills among children who are learning to read and write" (p. 909), it appears that at Hollow Creek Elementary, this distinction is somewhat blurry. One teacher commented on how she works with her students to use Standard English in both their speech and writing:

We leave the endings of words off and we say words differently than some other people say them and it might be difficult for us to spell [and write] them because of the way we say them. So, that's

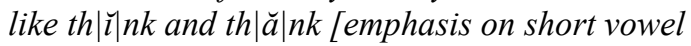
sounds]. They th|ă|nk [meaning th| $|\mathbf{l}| n k]$ about things sometimes. And that's one that we talked about just this week because we've been working on both those words, about how it's really suppose to be th|ü|nk and $w \mid$ a|sh [emphasis on schwa sound] is suppose to be w|a|sh not w|ar|sh [emphasis on " $r$ " sound] (interview transcript). (Julie)

Still another teacher shared, Well, I know that right now with these kids being so young, I think it's important to break them of some of the habits that they have now with their language and their writing. While most Hollow Creek Elementary teachers were adamant that their students use standard grammar, they seemed hesitant to openly discuss dialectal issues with their students.

\section{Dialect as an Obstacle}

Similar to findings of Perry and Delpit (1998), Hollow Creek Elementary teachers consider a nonstandard dialect to be a potential obstacle for students. Specifically, they believe that the use of dialect 
sometimes causes cognitive misunderstandings. For example, Sally shared how dialect interfered with a student's comprehension of verbal directions.

A couple of years ago I was doing a 'following the directions page' and I was giving them directions and they had to do an art project on this paper. And I said draw two lines $l-i-n-e-s$ around something, and I took up their papers and this one little girl had these two little animals around her paper. And I called her up and said what is this? And she said, "You said to draw two lions." L- $i$ $o-n$-s. Then I thought lines $(l|\bar{l}| n s)$ [emphasis on long vowel sound], lions (l| $\mid \overrightarrow{\mid}$ ns) [emphasis on long vowel sound]. They sound the same... When I said them to myself I said the two words exactly the same... So I mean it can, the dialect, can, you know, hurt what you're trying to say and... [get] across.

Sally also described another incident in which a child's dialect hindered him from understanding the definition of a new vocabulary word: She introduced the class to a new book with the word 'pillar' in its title and asked for a volunteer to provide a definition of the word. One student raised his hand and said, Pillar's what you sleep on.

My own encounter with a first grader provides yet another example of how dialect can interfere with comprehension.

After Lily begins writing and informs me that she enjoys "writin'," I ask her to tell me what she likes about it. She smiles and says, "Well, I like the way it makes my tummy feel." Finding that a far more interesting response that any I had encountered that day, I asked her to explain what she means. She tells me how happy she feels when she is 'writin'. When she stops talking, I pick up my pencil, look at it and say, "Wow. I wish writing made me feel that good." With a confused expression, she says, "Oh, you meant writin'." Lily thought that I had said 'riding'. (field notes)

Some teachers also fear that always using a nonstandard dialect will cause students to suffer undue embarrassment. Gaye explained:

It's important to start at this young age making them aware because I was never made aware until college that I was using incorrect grammar. And every time that I did it, my teacher let me know and it was kind of embarrassing so I think it's important to start with them early so that they're aware of it.
Some teachers expressed further concern for their students in having to deal with society's misconceptions regarding the Appalachian accent. One teacher explained: People think those of us with Appalachian accents are ignorant hillbillies who all live in shacks with dirt floors. Another teacher shared a story of how her dialect once kept her from securing a job: Well, the first year that I wanted a teaching job, a principal told me that he wouldn't hire me because of my dialect-because I had a strong Appalachian dialect. In a fashion similar to DeRozier (2002), another teacher talked openly about her efforts to 'straighten up' her language, consciously use correct noun/verb agreements, and eliminate the word 'reckon' from her vocabulary.

\section{Dialectal Interferences}

Dialectal interferences were apparent in two areas, the impact of teachers' dialects and the impact of the home environment, that is, the speech patterns of parents and close relatives.

Interference of teachers' own dialect. Although the use of dialect in a community often fosters a sense of belonging, teachers at Hollow Creek Elementary believe that their students also need to learn how to use Standard English. However, because most of Hollow Creek Elementary teachers are from the Appalachian region and use the dialect themselves, it is not always easy for them to teach Standard English. Because of their familiarity with the dialect, they may overlook, intentionally or unintentionally, grammatical errors associated with dialect. One faculty member commented, there have been times when I wish I could turn that (dialect) off. Sally, too, reflected on the difficulty of teaching Standard English with an Appalachian accent:

I know when I'm teaching phonics it's very hard for me to say the short e sound. It's hard, in this part of, I think it's hard in this part of the nation, it's harder to say $p|\breve{e}| n$ than it is to say $p|\breve{l}| n$ [emphasis on short vowel sounds]. So I really have to stop and think about it. And if I'm teaching them without teaching phonics and I say go get your $p|\breve{e}| n$, I say to get your $p|\grave{l}| n$. I don't say go get your $p|\breve{e}| n$ ' (laughs). So I have a difficult time with that.

Teachers at Hollow Creek Elementary are in a unique position to model both the use of Standard English and non-Standard English. By highlighting their language choices, they can more easily bring attention to the concept of code-switching and help 
their students identify situations that are appropriate for Standard and/or non-Standard English.

Home interferences. Teachers acknowledged the major impact of home environment on speech and grammar usage. Gail shared that some teachers feel as though they are walking a tightrope when teaching Standard English in a community where the Appalachian dialect is common. Robin reflected on the delicate balance between honoring the dialect of the community and teaching her students to use Standard English: I know that dialect and where you're from is important, too, but I think it's so much more important for them to get the proper English. Robin also commented on the address dialect in ways that are respectful to parents: You'll step on the toes of parents if you say that is incorrect or that's not a word or we shouldn't use that. Harriett shared an incident in which she unintentionally offended a parent when correcting a child's written work in regards to dialect: I corrected some mistakes on a child's paper, and I actually had a parent come in and say, 'Why isn't this right? This is the way we speak. Why isn't it right?' Other teachers, too, commented on trying to avoid offending students and parents. For example, Mary observed, I try not to correct them out loud to where it hurts their feelings, and Samantha explained:

I just try to model and make sure that I'm using correct words and when they may use a word that might not be appropriate then I'll just try to restate what they've said, not draw any attention to it.

Teachers at Hollow Creek Elementary School remain sensitive to their students' community and culture and are careful to respectfully guide their students in the use of Standard English.

\section{Ways Teachers Address Dialect}

Teachers at Hollow Creek Elementary generally address dialect in one of two ways. First, they indirectly teach Standard English. Secondly, they employ direct teaching methods by modeling and discussing the use of code-switching skills.

Indirect teaching of Standard English. Because teachers feel concern about offending their students' parents and want to avoid embarrassing their students, some choose to address their students' incorrect grammar usage indirectly. For example, Susan believed that through teacher modeling of correct grammar her students will learn to speak in Standard English: I think they pick up on correct language....We do so much talking in first grade that they're going to be really exposed to the correct dialect and the correct way to talk." Julie, another first grade teacher agreed, stating: I just accept what they say and then try to model for them an acceptable [way], and by acceptable I mean what is considered grammatically correct in our English textbooks and those kinds of things. Julie believed that "through normal conversation, children will pick up the correct grammar."

Susan explained how she addressed correct language usage in her students' writing.

Usually, I let them share what they have [written] and then sometimes I will, you know, say another way I've heard that is and share the way I would have said it. Not that their way is wrong, but try to get them to understand that 'Yeah. I've heard it that way before. Now this is another way that the same thing could be said. '...I correct their grammar a lot of times by doing that. Just like if they said 'He were going to the store.' I might say, 'He was going to the store...Just in correcting it ... maybe if they hear it over and over and not really pointing to the fact that that was used incorrectly, but maybe if you hear the correct way over and over, just like the spelling if you see it the right way over and over. I hope you'll commit it to memory.

Sarah, too, commented on her approach to teaching the difference between community talk and Standard English:

I tell the kids that it (Standard English) just makes you sound more educated and that we're at school to learn and I know that we're around people who talk like that and there's nothing wrong with how they're talking. That's just fine, but we're learning the correct way to use English in school.

Although Speicher and Beilanski (2000) point out that modeling Standard English is a typical approach in teaching Standard English, there are problems with such a strategy. For example, teachers, who model Standard English, at other times may model informal registers and not highlight this distinction for their students. Stated differently, since speakers naturally use the language in which they are most comfortable, just because teachers are teachers does not necessarily mean that they always utilize and model Standard English.

Different registers or code-switching. Some teachers choose a more direct approach when dealing with these same issues. As Perry and Delpit (1998) advocate, these teachers teach their students to be aware of different registers or code-switching. 
Barbara, while not referring to the term 'codeswitching', described how she explained this concept to her students:

I tell them to put it down just like they would say it. And we talk about, as a matter of fact, we talk about different roles. Each one of [us] has a different role in life, many different roles. And we talk about how if we wrote a letter... because we were sick...too sick to come to school...to our mothers, it would sound one way: "Dear Mom, I can't get out of bed today. I'm so sick. I don't think I can make it downstairs to breakfast let alone gettin' on the school bus or going to school. I have to stay home today. Don't you agree? I'm burning up". What if we wrote that same message to a friend of ours? It would sound different. Like, "Dear Susie, ha ha. Guess where I am? I'm at home in the bed watching Price is Right while you're at school studying your head off. If you don't care, bring my books by. I might be able to get my work [done] tonight. By the way, I'm drinking a big Pepsi Cola, what are you doing?" And then if we took that same message and wrote it to our teacher it would sound totally different: "Dear Miss Whatever, I am so sorry that I can't be at school today. Mom says I need to stay in bed and recuperate. I'll miss everybody. And if you can send my homework with Susie, I'll have it finished tomorrow." So depending on the different roles we take when we write, naturally our language is going to reflect that.

Again, while not referring to the term codeswitching, other teachers commented on teaching students to exercise their awareness of language. Carolyn, for example, teaches her students to recognize when it is appropriate to use the dialect of the community and when it is less acceptable: I think it's important that they know it depends on the type of writing that they're doing. You know, in some writing it [dialect] is appropriate. And then for other writings, you know, it's not appropriate. Susan concurred:

I think they have to think about the form they're using. If they're going to send a letter to the editor of a newspaper, they wouldn't want to come across as a country bumpkin or, you know, they want to sound intelligent.

More to the point, Leslie, a first grade teacher, commented: If they're writing a letter to their friends, use common language. And if they're writing a speech then obviously they should use correct grammar. Although Leslie did not identify this practice as codeswitching, she did teach the concept by providing students with appropriate instances to use nonStandard English as well as Standard English.

\section{Practical Implications}

While teachers are cognizant of their own dialect, they may not consistently model Standard English on a daily basis. In fact, based on classroom observations, it may be a common practice for teachers in the school to only consciously model Standard English when the purpose is grammar usage or spelling. By providing teachers with the opportunity to openly acknowledge and discuss the quandary in recognizing the Appalachian dialect while teaching Standard English, teachers will begin to reflect on their own use of the Appalachian dialect, how they personally view the use of the dialect, and the impact it may have on their teaching.

Furthermore, teachers at Hollow Creek Elementary School understand and appreciate that the community at large is steeped in tradition and sometimes view the correction of children's written and spoken language as intrusive. Because of this conflict, teachers at the elementary school choose to indirectly teach Standard English and, as a result, may seldom openly address the differences in the Appalachian dialect in comparison to Standard English. Through professional development targeting the issue, teachers could benefit from strategies that could be used to directly teach Standard English while still being respectful of the Appalachian dialect. One such strategy is codeswitching, and, it should be noted, that there is some evidence that some teachers purposefully teach using different registers or code-switching skills. Given an open format, these teachers may become comfortable in sharing how they honor the Appalachian dialect and teach Standard English simultaneously.

The practical implications of this study also extend beyond rural Appalachian schools to rural schools in all fifty states and beyond. For example, as the face of rural America changes, unique dialects from other regions of the United States and the world may be become more common place in rural areas (Strange et al., 2012). By providing teachers with opportunities to become aware of their own dialect and strategies to teach Standard English while honoring dialect, they will be better prepared to provide language instruction for students from a diversified student population. In essence, teachers in rural schools should model for their students using Standard English, honoring dialect, and practicing code-switching skills. 


\section{Limitations and Recommendations for Further Research}

Limitations of this study include the small sample size of one school and twenty-five educators. Also, it must be noted that one rural elementary in the Appalachian region cannot adequately represent all rural schools or all schools in the Appalachian region or even within the targeted southern Appalachian region. Instead, it is hoped, rather, that this study will elevate readers' awareness of how dialect may be perceived by teachers and how that perception may impact the education of rural students in areas where usage of Standard English within the community is not the norm.

Additional research is needed to more fully understand how teachers perceive the Appalachian dialect in rural schools. One question that begs to be addressed is whether or not the Appalachian dialect is viewed similarly or differently by rural schoolteachers who are from the Appalachian area as opposed to those who are not of the region. To shed further light on the topic of dialect, a more global approach may be required: researchers should also examine the perceptions of rural schoolteachers regarding dialects in rural schools across the US and beyond.

\section{Conclusion}

Although Hollow Creek Elementary teachers are aware of their dialect, proud of their heritage, and recognize their dialect as part of their culture, it is imperative that they fully embrace their positions as role models for the students in both modeling Standard English and honoring the Appalachian dialect.

Two main findings emerged from this study. First, teachers at Hollow Creek Elementary School sometimes view the Appalachian dialect as an obstacle. They believe that total use of the dialect can lead to misunderstandings and perpetuate regional stereotypes. Teachers may benefit from professional development that allows them to explore their own dialectal issues in order to become more cognizant of their use of both Standard English and the Appalachian dialect. Such an approach may help students to honor their own dialect while developing skills in Standard English so that they can be successful in schools and in the wider community.

Second, teachers believe that their own dialect and that of their students, parents and the community sometimes impedes the teaching of Standard English. Teachers, therefore, would also benefit from opportunities to learn about the teaching of different registers or code-switching skills, so that they help students understand language variation and become situationally aware of using language that is appropriate for different audiences

\section{References}

Abramson, R., \& Haskell, J. (Eds.). (2006). Encyclopedia of Appalachia. Knoxville,TN: The University of Tennessee Press.

Appalachian Regional Commission. (ARC, 2012).

Retrieved from http://www.arc.gov/index.do?nodeId=1

Baldwin, J. (1998). If Black English isn't a language, then tell me, what is it? In T. Perry \& L. Delpit (Eds.), The real Ebonics debate: Power, language, and the education of African, American children (pp. 67-70). Boston, MA: Beacon Press.

Barker, G. (1995). Notes from a native son: Essays on the Appalachian experience. Knoxville, TN: The University of Tennessee Press.

Beaumont, K. (1995). I ain't gonna paint no more. New York: Harcourt Press.

Billings, D., Norman, G., \& Ledford, K. (Eds.). (1999). Back Talk from Appalachia: Confronting stereotypes. Lexington, KY: University of Kentucky Press.

Brice-Heath, S. H. (1983). Way with words. New York: Cambridge University Press.
Cheatham, G., Armstrong, J., \& Santos, R. (2009). "Ya'll listenin?: Accessing children's dialect in preschool. Young Exceptional Children, 12(4), 214.

Constantz, G. (2006). Ecology. In R. Abramson, \& J. Haskell (Eds.), Encyclopedia of Appalachia (pp. 39-44). Knoxville, TN: The University of Tennessee Press.

Crotteau, M. (2007). Honoring dialect and culture: Pathways to student success on high-stakes writing assessments. English Journal, 96(4), 27-32.

Csak, N. (2002). "What's important when you're six?": Valuing children's oral stories. Language Arts, 79(6), 488-497.

Davidson, M., Howell, K., \& Hoekema, P. (2000). Effects of ethnicity and violent content on rubric scores in writing samples. Journal of Educational Research, 93(6), 367-374.

Delpit, L., \& Dowdy, J. K. (Eds.). (2002). The skin that we speak: Thoughts on language and culture in the classroom. New York: The New Press.

Delpit, L. (1998). What should teachers do?: Ebonics and culturally responsive instruction. In T. Perry \& 
L. Delpit (Eds.), The real Ebonics debate: Power, language, and the education of African, American children (pp. 17-28). Boston, MA:Beacon Press.

DeRosier, L. S. (2003). Songs of life and grace. Lexington, KY: University of Kentucky Press.

Dyer, J. (Ed.). (1998). Bloodroot: Reflections on place by Appalachian women writers. Lexington, KY: The University of Kentucky Press.

Higgs, R., Manning, A., \& Miller, J. W. (Eds.). (1995). Appalachian inside out: Culture and custom. Knoxville, TN: University of Tennessee Press.

Lippi-Green, R. (1997). English with an accent: Language, ideology, and discrimination in the United States. London: Routledge.

Montgomery, M. (2006). Language. In R. Abramson, \& J. Haskell (Eds.), Encyclopedia of Appalachia (pp. 999-1005). Knoxville, TN: The University of Tennessee Press.

Obermiller, P. \& Howe, S. (2000). Appalachian migration patterns, 1975- 1980 and 1985-1990. Appalachian Regional Commission. Retrieved from http://www.arc.gov/images/reports/migration/migr at.pdf

Perry, T. 1998). "I "on know why they be trippin"”: Reflections on the Ebonics debate. In T. Perry, \& L. Delpit, (Eds.), The real Ebonics debate: Power, language, and the education of African, American children (pp. 3-16). Boston, MA: Beacon Press.

Purcell-Gates, V. (2002). “...As soon as she opened her mouth!": Issues of literacy,

language, and power. In L. Delpit, \& J.K. Dowdy (Eds.), The skin that we speak: Thoughts on language and culture in the classroom (pp. 121141). New York: The New Press.
Purcell-Gates, V. (1995). Other people's words: The cycle of low literacy. Cambridge, MA: Harvard University Press.

Reese, B. (1995). Ray Hicks and the oral rhetorical traditions of southern Appalachia. In R. Higgs, A. Manning, \& J. W. Miller (Eds.), Appalachian inside out: Culture and custom (pp. 492-504). Knoxville, TN: University of Tennessee Press.

Smith, E. (2002). What is Black English? What is Ebonics? In T. Perry \& L. Delpit (Eds.), The real Ebonics debate (pp. 38-48). Boston, MA: Beacon Press.

Speicher, B. \& Bielanski, J. (2000). Critical thoughts on teaching Standard English. Curriculum Inquiry, 30(2), 147-170.

Strange, M., Johnson, J., Showalter, D., \& Klein, R. (2012). Why rural matters 2011-12:The condition of rural education in the 50 states. Washington, D.C.: Rural School and Community Trust.

Taylor, D. (1998). Family literacy: Young children learning to read and write. Portsmouth, $\mathrm{NH}$ : Heineman.

Terry, N. (2006). Relations between dialect variation, grammar, and early spelling skills. Reading and Writing, 19(9), 907-931.

Wilkinson, C. (1999). On being "country": One Affrilachian woman's return home. In

D. Billings, G. Norman, \& K. Ledford (Eds.). Back talk from Appalachia (pp. 184-186). Lexington, KY: The University of Kentucky Press.

Wolfram, W. (1998). American English: Dialects and variation. Oxford, UK: Blackwell.

Wolfram, W., \& Schilling-Estes, N. (2006). American English. Oxford, UK: Blackwell.

\section{About the author:}

Kathy Brashears, a former principal and teacher at the elementary level, is currently an associate professor for Tennessee Technological University. She teaches literacy courses for both undergraduates and graduates while conducting research, mainly targeting literacy practices within the Appalachian region. 